\title{
Decision-making Evolution of Remanufacturing Supply Chain Considering Retailer's Sales Efforts
}

\author{
Suxia Liu, Yuqing Zhu and Wei Zheng \\ School of Management, Jiangsu University, Zhenjiang Jiangsu 212013, China
}

\begin{abstract}
In this study, a remanufacturing supply chain consisting of a single manufacturer and a single retailer is considered, and a Stackelberg game model with the manufacturer as the leader and the retailer as the follower is built. The changes of decision-making in two different cases have been compared and analyzed. It shows that the increase in retailer's sales efforts, can effectively enhance the product wholesale and retail prices, and further enhance the profits of the manufacturers and retailers. Finally, the conclusion is verified by numerical simulation.
\end{abstract}

Keywords-remanufacturing supply chain; stackelberg game; sales efforts; decision-making

\section{INTRODUCTION}

Retailer's sales efforts and the retail prices of products are two important factors of the market demand. In order to increase the market demand, retailers tend to increase their advertising investment, train professional sales staff and enhance their sales efforts to sell products. The promotion of sales efforts often have a significant impact on supply chain decision making.

At present, there are a lot of literatures on the retailer's sales efforts. Taylor (2002) suggests that retailer's sales efforts can affect demand, and that different contractual combinations must be implemented in order to achieve supply chain coordination. Karry (2013) studied the optimal order of manufacturing efforts for manufacturers and retailers. Yue (2013) studied the optimal decision-making problem of advertising investment and the different decision-making of decision makers is built. Wang and Gercha (2001) studied the manufacturer's ability to use inventory as a compensation to stimulate retailers' efforts and use commodity shelf space as a retailer's effort variable. Jeuland and Shugan (1983) found that in a simple supply chain consisting of one supplier and one retailer, the price discount contract could correct the "double marginal" of the wholesale price contract in a deterministic demand scenario. In order to reduce the number of products returned by consumers, manufacturers must make a decision on whether to invest in product quality, so that retailers can improve product sales through their sales efforts (Zhu, Zhang and Tsung, 2007). Manufacturers develop effective incentive contracts, in order to encourage retailers to pay enough sales efforts (Chen, 2005), and retailers can get more pay by raising the level of effort to sell their products (Saha, 2013). Krishnan, Kapuscinski and Butz (2004) found that the improved repurchase mechanism could coordinate the supply chain by considering retailers' first-looking needs and then determining their level of effort (Krishnan, Kapuscinski and Butz, 2004).

Most literature focuses on building supply chain contracts and coordination However, in the supply chain, there are not many studies that consider how retailer's sales efforts have a specific impact on supply chain members. Therefore, this paper, in consideration of the competition between traditional manufacturers and retailers, introduces the retailer's sales efforts and compares the traditional competition with considering the retailer's sales efforts of supply chain decision-making.

\section{MODEL DESCRIPTION}

In this paper, a closed-loop supply chain composed of a single manufacturer and a single retailer is studied, and a Stackelberg game model that the manufacturer as the leader and retailer as the follower. The manufacturer produces new products and recycles wasted products. The retailer sells both new and remanufactured products. The structure of the paper can be shown as followed:

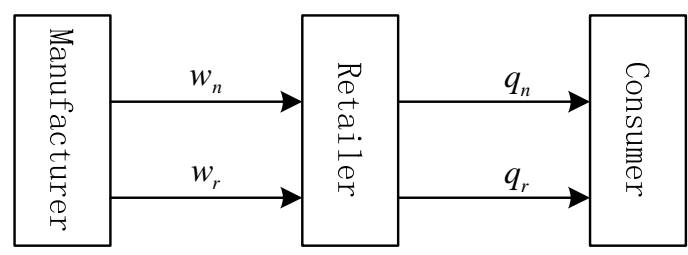

FIGURE I. SUPPLY CHAIN SYSTEM

\section{A. Model Parameters and Variables}

The parameters used in this article are as followed: 
TABLE I. THE PARAMETERS AND VARIABLES USED IN THIS ARTICLE

\begin{tabular}{lc}
\hline Model parameters and variables & Model parameters and variable meanings \\
$Q_{0}$ & Market size \\
$p_{n}, p_{r}$ & Prices of new and remanufactured products \\
$w_{n}, w_{r}$ & Wholesale prices of new and remanufactured products \\
$q_{n}, q_{r}$ & offered by the manufacturer \\
$c_{n}, c_{r}$ & Demand quality of new and remanufactured products \\
$\pi_{m}, \pi_{r}$ & Costs of new and remanufactured products \\
$\delta \in(0,1)$ & Profit of the manufacturer and retailer \\
$\gamma_{n}, \gamma_{r}$ & Consumer environment awareness \\
$t_{n}, t_{r}$ & Sale efforts of new products and remanufactured products \\
& by the retailer \\
\hline
\end{tabular}

\section{B. Demand Function}

In this model, it is assumed that the market size is $Q_{0}$ and consumers' valuation per unit of quality for new products is $v$, is a uniformly distributed random variable in the range of $v \in\left(0, Q_{0}\right)$. Then it is assumed that consumers' valuation of per unit of quality for remanufactured products is a fraction $\delta \in(0,1)$ of the valuation for new products, it means that consumers' valuation of per unit of quality for remanufactured products is $\delta v$. In the paper, it is assumed that $\delta=0.6$ which means that there are both new and remanufactured products in the market. Only when consumers' valuation for new products or remanufactured products is greater than the price he willing to pay will consumer choose to by new or remanufactured products. If consumer wants to buy new products, it must meet the following restrictions(Subramanian and Subramanya, 2012) :

$$
\left\{\begin{array}{c}
v-p_{n} \geq 0 \\
v-p_{n} \geq \delta_{v}-p_{r}
\end{array},\right. \text { and if consumer wants to buy }
$$

remanufactured products it must meet the following restrictions: $\left\{\begin{array}{c}\delta v-p_{r} \geq 0 \\ v-p_{n}<\delta v-p_{r}\end{array}\right.$. The study only takes the condition that the consumers both have demands for new and remanufactured products into account, that is to say $p_{n}-(1-\delta)<p_{r}<\delta p_{n}$. As a result, demand qualities of new and remanufactured products are given as follows:

$$
\begin{gathered}
q_{n}=\int_{\frac{p_{n}-p_{r}}{1-\delta}}^{Q_{0}} d F(v)=Q_{0}-\frac{p_{n}-p_{r}}{1-\delta} \\
q_{r}=\int_{\frac{p_{r}}{\delta}}^{\frac{p_{n}-p_{r}}{1-\delta}} d F(v)=\frac{\delta p_{n}-p_{r}}{\delta(1-\delta)}
\end{gathered}
$$

According to reference[11] (Kovach, 2014), demand qualities of new and remanufactured products are given as follows when considering sale efforts by the retailer:

$$
\begin{aligned}
& q_{n}=Q_{0}-\frac{\left(p_{n}-p_{r}\right)-\left(\gamma_{n} t_{n}-\gamma_{r} t_{r}\right)}{1-\delta} \\
& q_{r}=\frac{\delta p_{n}-p_{r}-\left(\delta \gamma_{n} t_{n}-\gamma_{r} t_{r}\right)}{\delta(1-\delta)}
\end{aligned}
$$

\section{Scenario 1:Retailer's Decisions without Sales Efforts}

In this scenario, first, the manufacturer determines the wholesale price of new and remanufactured products $w_{n}, w_{r}$. Second, the retailer determines the retailing price of new and remanufactured products in order to maximize its own profit:

$$
\begin{gathered}
\pi_{r}=\left(p_{n}-w_{n}\right)\left(Q_{0}-\frac{p_{n}-p_{r}}{1-\delta}\right)+\left(p_{r}-w_{r}\right)\left[\frac{\delta p_{n}-p_{r}}{\delta(1-\delta)}\right] \\
\pi_{r}=\left(p_{n}-w_{n}\right)\left(Q_{0}-\frac{p_{n}-p_{r}}{1-\delta}\right)+\left(p_{r}-w_{r}\right)\left[\frac{\delta p_{n}-p_{r}}{\delta(1-\delta)}\right]
\end{gathered}
$$

The Hesse matrix of the retailer's profit function is $H=\left(\begin{array}{cc}\frac{-2}{1-\delta} & \frac{2}{1-\delta} \\ \frac{2}{1-\delta} & \frac{-2}{\delta(1-\delta)}\end{array}\right), \quad|H|>0, \frac{\partial^{2} \pi_{r}}{\partial p_{n}{ }^{2}}=\frac{-2}{(1-\alpha)}<0$, the Hesse matrix is negative, as a result, the retailer's profit function has an optimal solution. Then take first derivatives of $\pi_{r}$ with respect to $p_{n}$ and $p_{r}$, then it can be obtained the following formulas:

$$
\begin{gathered}
\frac{\delta \pi_{r}}{\delta p_{n}}=\frac{w_{n}-w_{r}+2 p_{r}-2 p_{n}+(1-\delta) Q_{0}}{1-\delta} \\
\frac{\delta \pi_{r}}{\delta p_{r}}=\frac{w_{r}-\delta w_{n}+2 \delta p_{n}-2 p_{r}}{\delta(1-\delta)}
\end{gathered}
$$


By Simultaneous equations (6) and (7) the price of new products can be solved :

$$
p_{n}^{*}=\frac{\left(Q_{0}+w_{n}\right)}{2}, p_{r}^{*}=\frac{\left(\delta Q_{0}+w_{r}\right)}{2}
$$

In the second stage, the manufacturer determines the wholesale price of the new product and the remanufacturer according to the retailer's selling price. The manufacturer's profit is:

$$
\pi_{m}=\left(w_{n}-c_{n}\right) q_{n}+\left(w_{r}-c_{r}\right) q_{r}
$$

In the same way, it is easy to prove that the Hesse matrix of the manufacturer's profit function is negative. Therefore, the profit function of the manufacturer is the concave function, so the optimal solution exists, and the first-order partial derivative is obtained by summing the equation (9):

$$
\begin{gathered}
\frac{\delta \pi_{m}}{\delta w_{n}}=\frac{c_{n}-c_{r}+(1-\delta) Q_{0}-2 w_{n}+2 w_{r}}{2(1-\delta)}=0 \\
\frac{\delta \pi_{m}}{\delta w_{r}}=\frac{-\delta c_{n}+c_{r}+2 \delta w_{n}-2 w_{r}}{2 \delta(1-\delta)}=0
\end{gathered}
$$

By Simultaneous equations (10) and (11), the wholesale prices of new and remanufactured products offered by the manufacturer can be obtained :

$$
w_{n}^{*}=\frac{c_{n}-c_{1}+Q_{0}}{2}, w_{r}^{*}=\frac{c_{r}-c_{2}+\delta Q_{0}}{2}
$$

Substituting equation (12) into equation (8), demand quality of new and remanufactured products are calculated by equation (1) and equation (2): $p_{n}^{*}=\frac{c_{n}+3 Q_{0}}{4}, p_{r}^{*}=\frac{c_{r}+3 \delta Q_{0}}{4}$ $q_{n}^{*}=\frac{c_{r}-c_{n}+(1-\delta) Q_{0}}{4(1-\delta)}, q_{r}^{*}=\frac{\delta c_{n}-c_{r}}{4 \delta(1-\delta)}$ then, the optimal profit function of the manufacturer and the remanufacturer is obtained as follows:

$$
\begin{aligned}
& \pi_{m}=\frac{(1-\delta) \delta Q_{0}^{2}+\delta c_{n}^{2}+c_{r}^{2}-2 \delta c_{n} c_{r}-2 \delta c_{n}(1-\delta) Q_{0}}{8(1-\delta) \delta} \\
& \pi_{r}=\frac{(1-\delta) \delta Q_{0}^{2}+\delta c_{n}^{2}+c_{r}^{2}-2 \delta c_{n} c_{r}-2 \delta c_{n}(1-\delta) Q_{0}}{16(1-\delta) \delta}
\end{aligned}
$$

\section{Scenario 2:Retailer's Decisions with Sales Efforts}

The situation is the same as in case 1 , where the first-stage of manufacturer is to determine the wholesale price of new products and remanufactured products, and then the retailer sets the optimal price for the new product and the remanufacturer products according to the market demand for them. to maximize their own profits:

$$
\begin{aligned}
& \pi_{r}=\left(p_{n}-w_{n}\right)\left[Q_{0}-\frac{\left(p_{n}-p_{r}\right)-\left(\gamma_{n} t_{n}-\gamma_{r} t_{r}\right)}{1-\delta}\right]+ \\
& \left(p_{r}-w_{r}\right)\left[\frac{\delta p_{n}-p_{r}-\left(\delta \gamma_{n} t_{n}-\gamma_{r} t_{r}\right)}{\delta(1-\delta)}\right]
\end{aligned}
$$

According to the above analysis, the Hesse matrix of the retailer's profit function is negative. Therefore, the profit function of the retailer has the optimal solution. For the first-order partial derivative of the sum of the equation (15), the first order condition is as follows:

$$
\begin{gathered}
\frac{\delta \pi_{r}}{\delta p_{n}}=\frac{w_{n}-w_{r}-2 p_{n}+2 p_{r}+(1-\delta) Q_{0}+t_{n} \gamma_{n}-t_{r} \gamma_{r}}{1-\delta} \\
\frac{\delta \pi_{r}}{\delta p_{r}}=\frac{w_{r}-\delta w_{n}+2 \delta p_{n}-2 p_{r}-\delta t_{n} \gamma_{n}+t_{r} \gamma_{r}}{\delta(1-\delta)}
\end{gathered}
$$

By Simultaneous equations (16) and (17), it can be obtained:

$$
p_{n}^{*}=\frac{\left(Q_{0}+w_{n}+t_{n} \gamma_{n}\right)}{2}, p_{r}^{*}=\frac{\left(\delta Q_{0}+w_{r}+t_{r} \gamma_{r}\right)}{2}
$$

In the second stage, the manufacturer determines the wholesale price of the new product and the remanufactureraccording to the retailer's selling price. The manufacturer's profit is:

$$
\pi_{n}=\left(w_{n}-c_{n}\right) q_{n}+\left(w_{r}-c_{r}\right) q_{r}
$$

In the same way, it is easy to prove that the Hesse matrix of the manufacturer's profit function is negative. Therefore, the profit function of the manufacturer is the concave function, so the optimal solution exists, and the first-order partial derivative is obtained by summing the equation (19):

$$
\begin{aligned}
& \frac{\delta \pi_{m}}{\delta w_{n}}=\frac{c_{n}-c_{r}+(1-\delta) Q_{0}-2 w_{n}+2 w_{r}+t_{n} \gamma_{n}-t_{r} \gamma_{r}}{2(1-\delta)}=0 \\
& \frac{\delta \pi_{m}}{\delta w_{r}}=\frac{-\delta c_{n}+c_{r}+2 \delta w_{n}-2 w_{r}-\delta t_{n} \gamma_{n}+t_{r} \gamma_{r}}{2(1-\delta) \delta}=0
\end{aligned}
$$

By Simultaneous equations (20) and (21), the wholesale prices of new and remanufactured products offered by the manufacturer can be obtained :

$$
w_{n}^{*}=\frac{\left(c_{n}+Q_{0}+t_{n} \gamma_{n}\right)}{2}, w_{r}^{*}=\frac{\left(c_{r}+\delta Q_{0}+t_{r} \gamma_{r}\right)}{2}
$$

Substituting equation (22) into equation (18), demand quality of new and remanufactured products are calculated by equation (1) and equation (2): 


$$
\begin{aligned}
& p_{n}^{*}=\frac{1}{4}\left(c_{n}+3\left(Q_{0}+t_{n} \gamma_{n}\right)\right), p_{r}^{*}=\frac{1}{4}\left(c_{r}+3 \delta Q_{0}+3 t_{r} \gamma_{r}\right) \\
& q_{n}^{*}=\frac{(1-\delta) Q_{0}-c_{n}+c_{r}+t_{n} \gamma_{n}-t_{r} \gamma_{r}}{4(1-\delta)}, q_{r}^{*}=\frac{\delta c_{n}-c_{r}+t_{n} \gamma_{n}+t_{r} \gamma_{r}}{4 \delta(1-\delta)}, \text { then, }
\end{aligned}
$$

the optimal profit function of the manufacturer and the remanufacturer is obtained as follows:

$$
\begin{aligned}
& \pi_{m}=\frac{(1-\delta) \delta Q_{0}^{2}+\delta c_{n}^{2}+c_{r}^{2}-2 \delta c_{n} c_{r}-2 \delta c_{n}(1-\delta) Q_{0}}{8(1-\delta) \delta} \\
& +\frac{2 \delta t_{n} \gamma_{n}(1-\delta) Q_{0}+\delta t_{n}^{2} \gamma_{n}^{2}-2 \delta t_{n} \gamma_{n} t_{r} \gamma_{r}}{8(1-\delta) \delta} \\
& +\frac{t_{r}^{2} \gamma_{r}^{2}-2 \delta\left(t_{n} \gamma_{n}-t_{r} \gamma_{r}\right) c_{n}-2\left(\delta t_{n} \gamma_{n}-t_{r} \gamma_{r}\right) c_{r}}{8(1-\delta) \delta}
\end{aligned}
$$

$$
\begin{aligned}
& \pi_{r}=\frac{(1-\delta) \delta Q_{0}^{2}+\delta c_{n}^{2}+c_{r}^{2}-2 \delta c_{n} c_{r}-2 \delta c_{n}(1-\delta) Q_{0}}{16(1-\delta) \delta} \\
& +\frac{2 \delta t_{n} \gamma_{n}(1-\delta) Q_{0}+\delta t_{n}^{2} \gamma_{n}^{2}-2 \delta t_{n} \gamma_{n} t_{r} \gamma_{r}+t_{r}^{2} \gamma_{r}^{2}}{16(1-\delta) \delta} \\
& -\frac{2 \delta\left(t_{n} \gamma_{n}-t_{r} \gamma_{r}\right) c_{n}-2\left(\delta t_{n} \gamma_{n}-t_{r} \gamma_{r}\right) c_{r}}{16(1-\delta) \delta}
\end{aligned}
$$

\section{COMPUTATION RESUltS}

According to the above process, the calculation results of these two cases that considering retailer's sales efforts and not considering retail's sales efforts, are shown in TABLE II.

TABLE II. DECISION- MAKING RESULTS OF MANUFACTURERS AND RETAILERS IN DIFFERENT SITUATIONS

\begin{tabular}{cll}
\hline & not considered retailer's sales efforts & considered retailer's sales efforts \\
\hline$p_{n}$ & $\frac{\left(c_{n}+3 Q_{0}\right)}{4}$ & $\frac{\left[c_{n}+3\left(Q_{0}+t_{n} \gamma_{n}\right)\right]}{4}$ \\
$p_{r}$ & $\frac{\left(c_{r}+3 \delta Q_{0}\right)}{4}$ & $\frac{\left(c_{r}+3 \delta Q_{0}+3 t_{r} \gamma_{r}\right)}{4}$ \\
$w_{n}$ & $\frac{\left(c_{n}+Q_{0}\right)}{2}$ & $\frac{\left(c_{n}+Q_{0}+t_{n} \gamma_{n}\right)}{2}$ \\
$w_{r}$ & $\frac{\left(c_{r}+\delta Q_{0}\right)}{2}$ & $\frac{\left(c_{r}+\delta Q_{0}+t_{r} \gamma_{r}\right)}{2}$ \\
$q_{n}$ & $\frac{(1-\delta) Q_{0}-c_{n}+c_{r}}{4(1-\delta)}$ & $\frac{(1-\delta) Q_{0}-c_{n}+c_{r}+t_{n} \gamma_{n}-t_{r} \gamma_{r}}{4(1-\delta)}$ \\
$q_{r}$ & $\frac{\delta c_{n}-c_{r}}{4 \delta(1-\delta)}$ & $\frac{\delta c_{n}-c_{r}+t_{n} \gamma_{n}+t_{r} \gamma_{r}}{4 \delta(1-\delta)}$ \\
\hline
\end{tabular}

As shown in Table II, by comparing the two cases that considering retailer's sales efforts and not considering retailer's sales efforts, the more the retailer pays in the sales process, the higher the prices will be. It suggests that incentives should be adopted in the supply chain sales network to encourage retailers to sell their products, which will help increase the profits of retailers and manufacturers. In contrast to remanufactured products, the wholesale and retail prices of new products grow slightly more than the wholesale and retail prices of remanufacturers with the retailer's sales efforts increasing. On the one hand the result demonstrates that it is more likely to increase their profits by take effort to sell new products than remanufactured products; on the other hand it also shows that the government should increase subsidies for remanufactured products, to make it not in a great disadvantage in the process of selling new products at the same time.

For the retailer, consumers demand for remanufactured products is increasing with their growing sales efforts while the increase in demand for new products depends on the cost of sales efforts of new products and remanufactures. When the unit cost of the new product is greater than the cost of the unit sales effort, the same amount of sales effort will increase the demand for new products. While the unit cost of the new product is less than the cost of the unit sales effort, the investment in the same level of sales effort will reduce the demand for new products.

\section{NUMERICAL CASE}

In the supply chain sales network, the retailer is at the end of the product sales and has direct access to the consumer. During the sales process, retailer's sales efforts tend to have an impact on the sale of the product. This section examines the impact of retailer's sales efforts on demand for new products and remanufactures, retail prices, wholesale prices, and profits.

By considering the constraint from facts, the value of parameters is as follows: $Q_{0}=1000, c_{n}=320, c_{r}=220$, $\delta=0.6, t_{n}=20, t_{r}=15, \quad \gamma_{n} \in(0,40), \gamma_{r} \in(0,40)$ Depending on the degree of effort by the retailer to sell the new product and remanufactured product, the change in the retailer sales effort can be made for the demand for new product and remanufacturing quantity, retail price, wholesale price and profit impact as shown in Figure II-IX. 


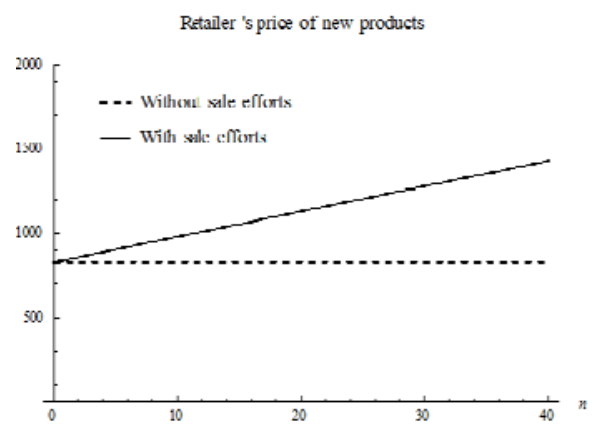

FIGURE II. NEW PRODUCT RETAIL PRICE TREND CHART

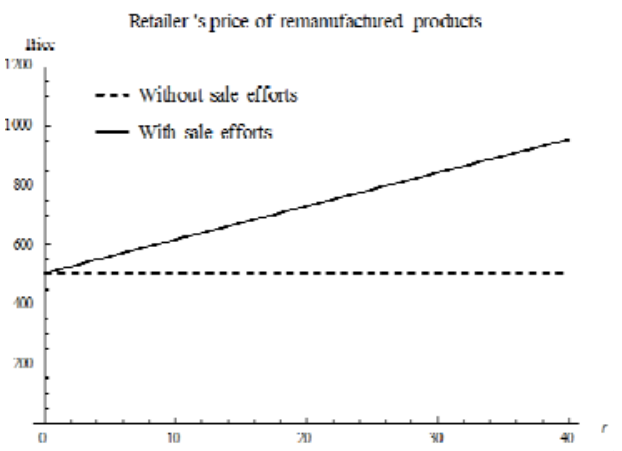

FIGURE III. REMANUFACTURED PRODUCT RETAIL PRICE TREND CHART

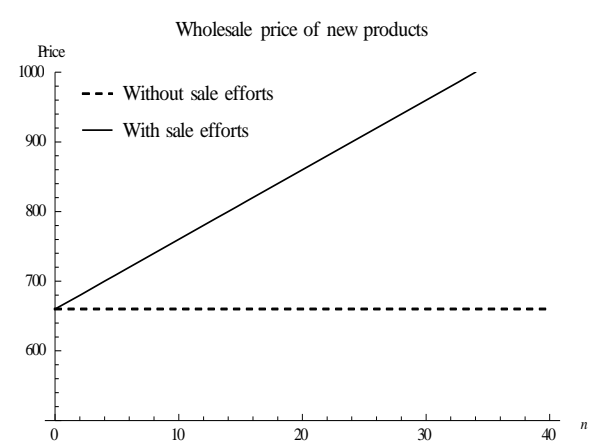

FIGURE IV. NEW PRODUCT WHOLESALE PRICE TREND CHART

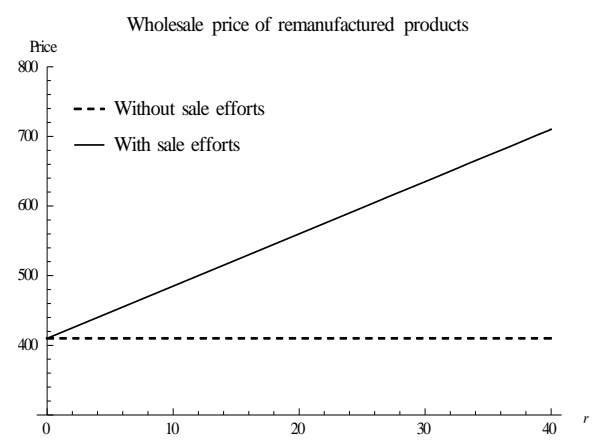

FIGURE V. REMANUFACTURED PRODUCT WHOLESALE PRICE TREND CHART

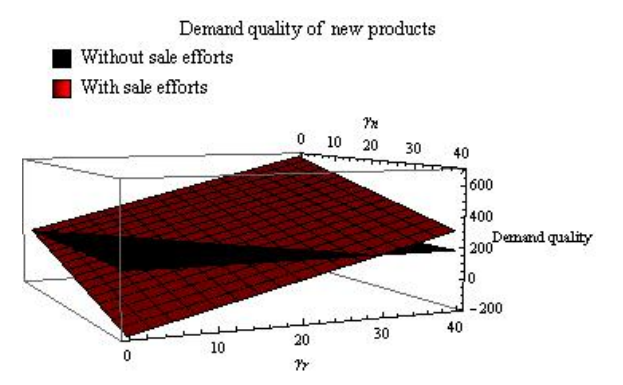

FIGURE VI. NEW PRODUCT DEMAND TREND CHART

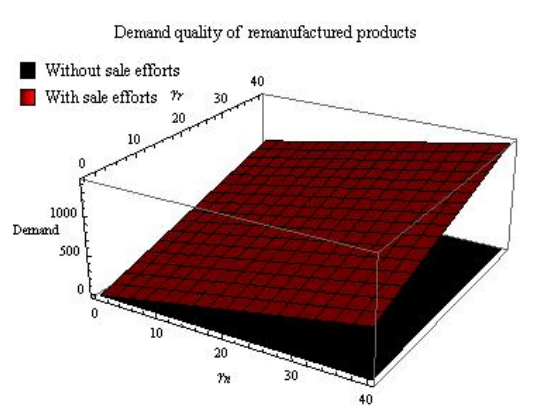

FIGURE VII. REMANUFACTURED PRODUCT DEMAND TREND CHART

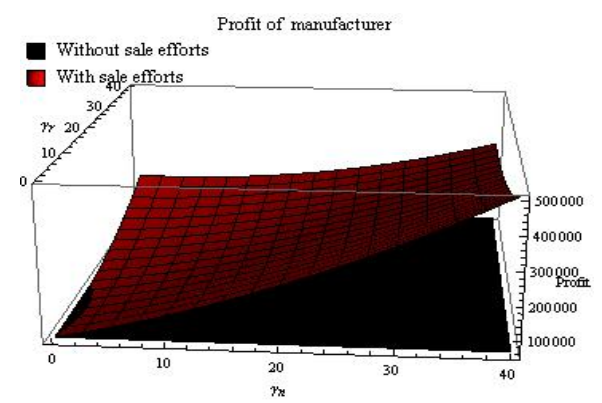

FIGURE VIII. MANUFACTURER PROFIT TREND CHART

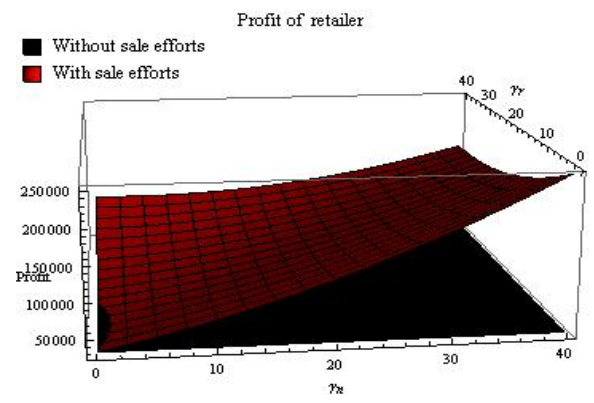

FIGURE IX. RETAILER PROFIT TREND CHART

As shown in Figure II-V, the wholesale and retail prices have a significant increase in both new product and remanufactured product with the improvement of the retailer's sales efforts, and the wholesale price and the retail price of products are in a positive relationship with the retailer's sales 
efforts. The more the retailer's effort is payed for selling products, the higher the wholesale price and the retail price will be. This also indicatess that in the process of product sales, the retailer can increase the degree of sales efforts to enhance the retail price of products to achieve the purpose of improving the profits. In addition, with the increase in product wholesale prices, manufacturers' profits will also be a certain degree of growth. As a result, the increase in retailer's sales efforts is conducive to the improvement of the profitability of remanufacturing supply chain members.

As can be seen from Figure VI, by comparing the two cases that considering retailer's sales efforts and not considering retailer's sales efforts, the demand for new products considering retailer's sales efforts get below the demand for new products that do not take retailer's sales efforts into account, when the extent to which the retailer sells new products is less than the degree of effort to sell remanufactured products, while the demand for new products considering retailer's sales efforts is higher than the demand for new products that do not take retailer's sales efforts into account, when the extent to which the retailer sells new products is higher than the degree of effort to sell remanufactured products. According to Figure VI, the demand for remanufactured products have increased to some extent as the retailers improve their sales efforts, whether they are new products or remanufactured products comparing with the case that retailer do not put into sales efforts of products. This demonstrates that the retailer's sales efforts to enhance the products can be conducive to sales, and a certain degree of sales efforts to remanufactured products and new products in the process of competition can gain advantage.

Figure VIII shows that, by comparing considering the retailer's sales effort and not considering the retailer's sales effort, the profit of the manufacturer is increasing as the retailer's sales efforts continue to increase. Only when the retailer takes effort to sell new products, the manufacturer's profit is to enhance the largest. The degree of effort increases when the retailer sells remanufactures, the manufacturer's profit is to a certain degree of decline, but compared to not consider the retailer's sales efforts, the manufacturer's profit increases to a certain extent. This also indicates that retailer's sales efforts can help to increase the profits of manufacturers of selling new products and remanufactured products. According to Figure IX, although the profit is lower than the case that only considering the sales efforts to new products, it is not only conducive to the sale of remanufactured products also increased the profits of retailers while taking the retailer efforts into account to sell new products and remanufactured products.

\section{V.CONCLUSIONS}

In this paper, the changes in the wholesale price, retail price and demand for the new product as the retailer's sales efforts at the end of the remanufacturing supply chain have been considered. And compare it to the remanufacturing supply chain which does not take retailer's sales efforts into account, to analyze its trends in wholesale price, retail price, demand, manufacturer profits and retailer profits.

By comparing the two cases that considering retailer's sales efforts and not considering retailer's sales efforts, it is shown that wholesale price and retail price of the product can increase to a certain extent, as the retailer increases the effort to sell the product, whether it's a new product or a remanufactured product. Different levels of effort may lead to a downward trend in demand for new products compared to those that do not take retailer's sales efforts into account, but the appropriate level of effort is both able to increase sales of new products and remanufactures. For the retailers and the manufacturers, their profit will increase if the retailers enhance product sales efforts. In real life, retailers at the end of sales should be more concerned about the extent to which retailers are investing in the process of selling products, often increasing profits across the supply chain.

In this paper, a remanufacturing supply chain of a manufacturer and a retailer is constituted, but in reality there may be a number of manufacturers and retailers in the supply chain. The cost is a fixed in this paper, but it may change in some situation. It can be further explored in future research.

\section{ACKNOWLEDGMENT}

This work was supported in part by the National Natural Science Foundation of China under grant 71403108, and by China Postdoctoral Science Foundation under grant 2016M590426, and by Jiangsu China Postdoctoral Science Foundation under grant 1501073C , and by Innovation Project of JiangSu Province to young teachers.

\section{REFERENCES}

[1] T. A. Taylor, "Supply Chain Coordination Under Channel Rebates with Sales Effort Effects”, Management Science, vol 48, no.2, pp.992-1007, 2002.

[2] S. Karray, "Periodicity of pricing and marketing efforts in a distribution channel”, European Journal of Operational Research, vol. 228, no. 3, pp.635-647, 2013.

[3] J. Yue, J. Austin, Z. Huang, B. Chen, "Pricing and advertisement in a manufacturer-retailer supply chain”, European Journal of Operational Research, vol.231, no.2, pp.493-502, 2013.

[4] Y. Wang, Y. Gerchak, "Supply chain coordination when demand is shelf-space dependent”, Manufacturing and Service Operations Management, vol. 3, no.1, pp.82-87, 2001.

[5] A. Jeuland, S. Shugan, "Managing channel profits", Management Science, vol.2, no.3, pp.239-272, 1983.

[6] K. Zhu, R.Q. Zhang, F. Tsung, "Pushing quality improvement along supply chains”, Management Science, vol.53, no.3, pp.421-436, 2007.

[7] F. Chen, "Salesforce Incentives, Market Information, and Production/Inventory Planning”, Management Science, vol.51, no.1, pp.60-75, 2005.

[8] S. Saha, "Supply chain coordination through rebate induced contracts", Transportation Research Part E, vol.50, pp.120-137, 2013.

[9] H. Krishnan, Kapuscinski R., D. A. Butz, "Coordinating contracts for decentralized supply chains with retailer promotional effort”, vol.50, no.1, pp.48-63, 2004.

[10] R. Subramanian, R. Subramanyam, "Key factors in the market for remanufactured products”, Manufacturing \&Service Operations Management, vol.14, no.2, pp.315-326, 2012.

[11] J.J. Kovach, “Operational challenges of strategy execution”, Georgia Institute of Technology, 2014. 